\title{
Multiple Myeloma in Armenia During the Period 2006- 2018: Facts and Discussion
}

\section{Narine Ghazaryan ( $\nabla$ naringhazaryan@gmail.com )}

Laboratory of Toxinology and Molecular Systematics, Institute of Physiology

\section{Samvel Danelyan}

Hematology center after Yolyan

\section{Samvel Bardakhchyan}

Fundacao Hemominas

\section{Anahit Saharyan}

Yerevan State Medical University

\section{Lusine Sahakyan}

Hematology center after Yolyan

\section{Research article}

Keywords: multiple myeloma, prevalence, incidence, survival, Armenia

Posted Date: September 2nd, 2020

DOI: https://doi.org/10.21203/rs.3.rs-50131/v1

License: (c) (i) This work is licensed under a Creative Commons Attribution 4.0 International License. Read Full License

Version of Record: A version of this preprint was published at BMC Cancer on August 21st, 2021. See the published version at https://doi.org/10.1186/s12885-021-08676-w. 


\section{Abstract}

Background: It is well known that the increased incidence of hematological malignancies is mainly caused by the growth of non-Hodgkin's lymphoma and multiple myeloma (MM). The indicated annual increase of MM incidence in the world is $0.7 \%$. Despite significant advances in the MM treatment the mortality rates are reaching $0.8-1.7 \%$. The aim of the current study was a comprehensive analysis of $\mathrm{MM}$, i.e., their prevalence, incidence and survival rates in Armenia for the period of 2006-2018.

Methods: The initial data for this survey were derived from ambulance cards, hospitalization journals, and clinical data from the Registry of Blood Diseases at the Hematology Center named after Yeolyan. Additional data was acquired from the National center of oncology named after Fanarjian, as well as from death certificates.

Results: Data analysis showed that during the reported time period the increase of the MM incidence was 1.23 per 100000 population. In comparison to the results obtained for 1966-1971 and 1998-2004, a significant increase in incidence of MM was found.

Conclusions: The incidence rates for the MM increased during the analyzed period and women are particularly in the risk group. Moreover, attention should be paid to the fact that the most favorable age for male with MM is 59 years and below.

\section{Introduction}

The combat against hematological malignancies is primarily aimed at reducing prevalence, incidence, mortality and improving the quality of life of cancer patients through prevention, early diagnosis, effective therapy and palliative care. Among hematological malignancies, in terms of frequency, MM is the second, following after lymphomas, and account for $1 \%$ of all neoplasias, $2 \%$ of all deaths from neoplasias and $12-15 \%$ of onco-hematological diseases [1$5,8-14]$.

The incidence and prevalence of MM increases with age [16]. The MM is twice as common in men as women. Several studies have shown that the age-related incidence of MM varies throughout the world: from 0.5 per 100000 in Asian countries, 0.9-3.3 in European countries and 5-8.2 in the United States [1, 2, 24-31]. Interestingly, the rates of morbidity are also varying across different post-Soviet countries. Despite the fact that the incidence of MM has increased significantly in different parts of the world in the last 10-20 years, in some areas of the US and the UK it has reached its plateau and started declining [1, 15-23]. Age-standardized incidence and death rates are highest in the Australasian, North American, and Western European populations, and the lowest - in the Asia, Oceania, and subSaharan Africa $[5,18,22,29]$.

To the best of our knowledge, there have been no studies of MM morbidity in the Republic of Armenia so far. In order to fill this gap, the aim of this study was to identify patterns and trends in the incidence of MM in the Republic of Armenia from 2006 to 2018.

\section{Methods}

The main data source for this study was outpatient and dispensary cards, hospitalization journals, as well as clinical data from the Register of Blood Diseases of the Hematology Center after. prof. R. Yeolyan. This information has been supplemented by the data from National Oncological Centre after V.A. Fanarjyan as well as from death registration service at Ministry of Justice RA. Analysis of the demographic data on MM incidence in Armenia was carried out for 
the period of 2006-2018 (Table 1). Demographic indicators were derived from the database of Statistical Committee of Armenia (https://www.armstat.am/en/).

Table 1

Characteristics of patients with multiple myeloma diagnosed between 2006 and 2018 in Armenia

\begin{tabular}{|lll|}
\hline Characteristics & Number of patients & (\%) \\
\hline Gender & 242 & $(48.2)$ \\
Male & 260 & $(51.8)$ \\
Female & & \\
\hline Total & 502 & $(100)$ \\
\hline Age group & 3 & $(0.6)$ \\
$\mathbf{2 5 - 3 4}$ & 22 & $(4.4)$ \\
$\mathbf{3 5 - 4 4}$ & 103 & $(20.5)$ \\
$\mathbf{4 5 - 5 4}$ & 200 & $(39.8)$ \\
$\mathbf{5 5 - 6 4}$ & 127 & $(25.3)$ \\
$\mathbf{6 5 - 7 4}$ & 47 & $(9.4)$ \\
\hline $75+$ & 502 & $(100)$ \\
\hline Total & & \\
\hline Figures are numbers (with percentages in total number of patients). \\
\hline
\end{tabular}

Diagnosis of $\mathrm{MM}$ and the definition of the stage were carried out according to the criteria proposed by the International Myeloma Working Group [10]. The patients received melphalane and prednisolone (MP), cyclophosphamide and prednisolone (CP), vincristine, doxorubicin, and dexamethasone (VAD) and also according to new protocols other treatment such as (Cyclophosphamide, VELCADE, Doxorubicin and Dexamethasone (CVDD) [1, 4]. The response to the therapy was assessed according to the criteria of the European Group for Blood and Marrow Transplant (EBMT) guidebook [3]. Survival (OS) was determined by the period between the date of diagnosis and the date of death. Direct method of adjustment was used for elimination of possible influence of changes in age structure of population through passage of ten years. The time series data was analyzed using least squares regression analysis.

\section{Results And Discussion}

During the study period (2006-2018), 502 primary MM patients were registered and / or treated at the Hematological Center of Armenia. The median age was 60.6 years (range 31-89) with 260 (51.8\%) female and 242 (48.2\%) male patients. Table 1 shows the demographic characteristics of the patients. $75 \%$ of the patients were older than 55 years (Table 1). The average annual incidence was 1.2 per 100000 population. The average annual gender-specific incidence rates of MM in Armenia are presented in Figure 1. Linear analysis was conducted in relation to the incidence rates in general. Analysis of the annual average incidence rates of MM (fig. 1) revealed a tendency to a certain increase in the incidence rate in the period under study both for males and females. 
After direct adjustment still MM rates demonstrate a significant increase in 2018 compared to $2006,1.9$ vs. 0.7 per 100000 population. In general specific age and gender related patterns were not observed. In some cases, a higher incidence rate was registered among male and female $(2018,2012)$, in other cases among female $(2014,2018)$. In 2012 and 2017 the highest rate among female was recorded for age group 65-74, but in 2015 for older women. Interestingly for males incidence of MM was lowest at 45-54 age group (fig. 1 and 2).

We also calculated age-specific incidence rates with 95\% confidence intervals in 2006 and 2015 . The incidence rates in these figures are calculated for 100.000 populations of the specified age groups. The prevalence of the disease reaches its peak at the age of 75+ among male (7.3) and female (4.0) in 2006, and at the age of 65-74 among male (10.6) and female (8.3) in 2018.

The obtained results reveal a clearly expressed tendency to an increase in the incidence of MM (2.2 times), regardless of age and population size changes. Unlike most other hematologic malignancies in Armenia, MM was rare between 0-35 years old. The MM incidence rate was increased with age in most of the age groups, which was consistent with previous study in Armenia [6].

The average annual incidence rates of MM (Figure 4) increased in the last 12 years compared to those reported by early studies (1966-1971 and 1998-2004) [6]. We observed a significant increase in the incidence of MM during the three investigated periods.

A possible explanation to this can be improvements in MM diagnosis in Armenia. This upward trend of incidence may be explained partly by some factors such as aging, better access to diagnosis and excess body weight [25], but much of this trend was largely unexplained and further study focused on etiology of MM should be performed. Furthermore, other factors such as adverse environmental conditions could potentially increase risk of myeloma [30]. A number of studies have reported increasing MM incidence over time of the world too $[2,5,12,14,15,18]$.

In addition, we analyzed the survival parameters of 1-and 5-year of patients with MM. In this case, 1-and 5-year survival was determined in patients from 2006-2018 (Table 2). 
Table 2

Relative survival by period of follow-up for patients with multiple myeloma in Armenia. (1- and 5-year estimates with $95 \%$ confidence intervals)

\begin{tabular}{|c|c|c|c|c|c|c|c|c|c|c|c|c|}
\hline & \multicolumn{6}{|c|}{ 1year survival rates } & \multicolumn{6}{|c|}{5 year survival rates } \\
\hline & \multicolumn{2}{|l|}{ Total } & \multicolumn{2}{|l|}{ Male } & \multicolumn{2}{|c|}{ Female } & \multicolumn{2}{|l|}{ Total } & \multicolumn{2}{|l|}{ Male } & \multicolumn{2}{|c|}{ Female } \\
\hline & $\leq 60$ & $>60$ & $\leq 60$ & $>60$ & $\leq 60$ & $>60$ & $\leq 60$ & $>60$ & $\leq 60$ & $>60$ & $\leq 60$ & $>60$ \\
\hline 2006 & 100 & $83.3^{\star \star}$ & 100 & $80 * *$ & 100 & $85.7 * \star$ & 58.3 & $50 * *$ & 100 & $40 * *$ & 42.9 & $57.1^{\star *}$ \\
\hline 2007 & 87.5 & $100 * \star$ & 100 & 100 & 80 & $100 * *$ & 25 & $60 * *$ & 33.3 & $50 \star \star$ & 20 & $66.7^{\star \star}$ \\
\hline 2008 & 100 & $91.7^{\star \star}$ & 100 & 100 & 100 & $87.5^{\star \star}$ & 21.4 & $8.3^{\star \star}$ & 12.5 & $0 * \star$ & 33.3 & $12.5^{\star \star}$ \\
\hline 2009 & 44.4 & $38.9 * *$ & 50 & $100 * \star$ & 40 & $15.4^{\star \star}$ & 16.7 & 16.7 & 0 & $40 * *$ & 30 & $7.7 * \star$ \\
\hline 2010 & 82.6 & $73.7 \star \star$ & 42.9 & $63.6^{\star \star}$ & 100 & $87.5^{\star \star}$ & 17.4 & $15.8^{\star \star *}$ & 14.3 & $27.3^{\star \star}$ & 18.7 & $0 * *$ \\
\hline 2011 & 95.2 & $100 * \star$ & 90.9 & $100 * \star$ & 100 & 100 & 49.6 & $31.1^{\star \star}$ & 54.5 & $25^{\star \star}$ & 40 & $37.5^{\star \star}$ \\
\hline 2012 & 84 & 83.3 & 88.2 & 86.7 ** & 75 & $77.8^{\star \star *}$ & 20 & $20.8^{\star}$ & 23.5 & $26.7 * \star$ & 12.5 & $11.1^{\text {** }}$ \\
\hline 2013 & 80 & $71.4^{\star \star}$ & 81.2 & $100 * \star$ & 75 & $71.4^{\star \star}$ & 20 & $21.4^{\star \star}$ & 37.5 & $0 \star \star$ & 18.2 & $16.7^{\star \star *}$ \\
\hline 2014 & 77.3 & $82.4^{\star \star}$ & 75 & 75 & 80 & $88.9 * \star$ & - & - & - & - & - & - \\
\hline 2015 & 72.8 & $64.3^{\star \star}$ & 58.3 & $70 * \star$ & 90 & $61.1^{\star \star}$ & - & - & - & - & - & - \\
\hline 2016 & 60 & $76.9 * \star$ & 55.6 & 55.6 & 66.7 & $88.2^{\star \star}$ & - & - & - & - & - & - \\
\hline 2017 & 63.2 & $69.2^{\star \star}$ & 55.6 & $71.4^{\star *}$ & 70 & $75^{\star \star}$ & - & - & - & - & - & - \\
\hline 2018 & 47.2 & $47.4^{*}$ & 0 & $62.5^{\star \star}$ & 62.5 & $46.7 * \star$ & - & - & - & - & - & - \\
\hline Average & 76.5 & 76.3 & 69.1 & $81.9 * \star$ & 79.0 & 75.8 & 28.3 & 28.0 & 34.5 & 26.1 ** & 27.0 & $26.1^{\star}$ \\
\hline
\end{tabular}

According to the received data, during the study period 2006-2018 the average annual survival rate for both sex was $76.5 \%$ at age group 59 years and below and $76.3 \%$ in group 60 years and over. It is remarkable, that annual survival rates differ most only in male $69.1 \%$ at age group 59 years and below opposite $81.9 \%$ in group 60 years and over. These data are consistent with the results of researchers in different countries $[1,2,9,15]$. The analysis of age-related 5 years survival revealed that a prognostically favorable age for male was age group 59 years and below. Improving diagnosis and treatment techniques had a positive effect on survival rates of MM. According to the received data the 1 -year relative survival for both sexes increased for $14.1 \%$ ( $\leq 60$ age group) and $24.7 .6 \%$ (>60 age group) in the period of 2008-2010 to the period of 2011-2014 with the increased use of novel agents. The increasing of this is most pronounced at 5 year survival rates: for $61.6 \%$ and $79.4 \%$ respectively.

\section{Conclusion}

We observed that incidence rates for the MM increased during the analyzed period and women are particularly in the risk group. Moreover, attention should be paid to the fact that the most favorable age for male with MM is 59 years and below. Based on the disparities in MM burden, different strategies for disease prevention and control should be employed when health policy is developed in the future. 


\section{Abbreviations}

MM: Multiple Myeloma; MP: Melphalane and Prednisolone; CP: Cyclophosphamide and Prednisolone; VAD: Vincristine, Doxorubicin, and Dexamethasone; EBMT: European Group for Blood and Marrow.

\section{Declarations}

\section{Acknowledgments}

The authors would like to express our gratitude to the National Oncological Centre after V.A. Fanarjyan for their participation in the study.

\section{Authors' contributions}

NA: conception and design of the study, acquisition of data, drafting of the manuscript, and critical revision of the manuscript. LS: analysis and interpretation of data, drafting of the manuscript, and critically revising the manuscript for important intellectual content. SD, SB: acquisition of data, and critical revision of the questionnaire. AS: drafting of the manuscript and recruitment of participants.

\section{Funding}

No financial support was received for this study.

\section{Availability of data and materials}

Datasets for the current study are not publicly available to protect the anonymity of the respondents.

\section{Ethics approval and consent to participate}

The study was approved by the Institutional Review Board of Committee of Ethics of the Yerevan State Medical University (YSMU) (Yerevan, Armenia). Written informed consent was obtained from all participants.

\section{Consent for publication}

Not applicable.

\section{Competing interests}

The authors declare that they have no competing interests

\section{References}

1. Andres M, Feller A, Arndt V. Trends of incidence, mortality, and survival of multiple myeloma in Switzerland between 1994 and 2013. Cancer Epidemiol. 2018;53:105-10. 
2. Bora K. Distribution of multiple myeloma in India: Heterogeneity in incidence across age, sex and geography. Cancer Epidemiol. 2019;59:215-20.

3. 2019 The EBMT Handbook // Open Access (eBook), 688.

4. Costa L,J, Zhang MJ, Zhong X, et al., 2013 Trends in utilization and outcomes of autologous transplantation as early therapy for multiple myeloma. Biol. Blood Marrow Transplant., 19(11):1615-1624.

5. Cowan AJ, et al. Global Burden of Multiple Myeloma: A Systematic Analysis for the Global Burden of Disease Study 2016. JAMA oncology. 2018;4:9:1221-7.

6. Daghbashyan SS, Amirkhanyan ES, Meliksetyan KH, Khachatryan ES. Epidemiology of leukemia and lymphoma in Armenia according to 1998-2006. Blood. 2006;1(3):5-11.

7. Dimopoulos M, Spencer A, Attal M, et al. Multiple Myeloma (010) Study Investigators. Lenalidomide plus dexamethasone for relapsed or refractory multiple myeloma. N Engl J Med. 2007;357(21):2123-32.

8. Go RS, Bartley AC, Crowson CS, et al., 2017 Association between treatment facility volume and mortality of patients with multiple myeloma. // Journal of Clinical Oncology, 35:598-604.

9. Hungria V, Chiattone C, Pavlovsky M, et al. Epidemiology of Hematologic Malignancies in Real-World Settings: Findings from the Hemato-Oncology Latin America Observational Registry Study. Journal of Global Oncology. 2019;5:1-19.

10. International Myeloma Working Group. Criteria for the classification of monoclonal gammopathies, multiple myeloma and related disorders: a report of the International Myeloma Working Group, $2003 \mathrm{Br} \mathrm{J}$ Haematol., 121:749-757.

11. Kazandjian D. 2016 Multiple myeloma epidemiology and survival: A unique malignancy // Semin Oncol., 43/6:676-681.

12. Kim K, Lee JH, Kim JS, et al., 2014 Clinical profiles of multiple myeloma in Asia-An Asian Myeloma Network study. Am J Hematol., 89:751-756.

13. Kristinsson SY, Anderson WF, Landgren O. Improved long-term survival in multiple myeloma up to the age of 80 years. Leukemia. 2014;28(6):1346-8.

14. Kyle RA, Therneau TM, et al. Incidence of multiple myeloma in Olmsted County, Minnesota-Trend over 6 decades. Cancer. 2004;101:2667-74.

15. Hossain MS, Iqbal MS, Khan MA, et al., 2014 Diagnosed hematological malignancies in Bangladesh - a retrospective analysis of over 5000 cases from 10 specialized hospitals. BMC Cancer 14:438.

16. Liu J, Liu W, et al. Incidence and mortality of multiple myeloma in China, 2006-2016: an analysis of the Global Burden of Disease Study. Journal of Hematology Oncology. 2019;12:136-42.

17. Liu W, Liu J, Song Y, et al. Mortality of lymphoma and myeloma in China, 2004-2017: an observational study. J Hematol Oncol. 2019;12(1):22-8.

18. Costa LJ, Brill IK, et al. Recent trends in multiple myeloma incidence and survival by age, race, and ethnicity in the United States. Blood advances. 2017;1(4):282-7.

19. Philip S, Rosenberg, Kimberly A, et al. Future distribution of multiple myeloma in the United States by sex, age, and race/ethnicity. Blood. 2015;125:410-2.

20. Ramón V, Ingemar T, Ola L, et al. Incidence of multiple myeloma in Great Britain, Sweden, and Malmö, Sweden: the impact of differences in case ascertainment on observed incidence trends. BMJ Open. 2016;6:009584.

21. Ravindran A, Bartley AC, Holton SJ, et al., 2016 Prevalence, incidence and survival of smoldering multiple myeloma in the United States. Blood Cancer J., 6(10): 486. 
22. Renshaw C, Ketley N, Møller H, Davies E. Trends in the incidence and survival of multiple myeloma in South East England 1985-2004. BMC Cancer. 2010;10:74.

23. Santosh SP, Patel, Damiano R. Epidemiology, Biology, and Outcome in Multiple Myeloma Patients in different Geographical Areas of the World. Journal of Advances in Internal Medicine. 2012;1(1):20-32.

24. Smith BD, Smith GL, Hurria A, et al. Future of cancer incidence in the United States: burdens upon an aging, changing nation. J Clin Oncol. 2009;27(17):2758-65.

25. Sung H, Siegel RL, Torre LA, et al., 2019 Global patterns in excess body weight and the associated cancer burden. CA Cancer J Clin., 69(2):.88-112.

26. Tan D, Chng WJ, Chou T, et al., 2013 Management of multiple myeloma in Asia: resource-stratified guidelines. Lancet Oncol., 14:571-581.

\section{2015 UK CR}

Myeloma incidence statistics.

2015 UK CR. Myeloma incidence statistics.. http://www.cancerresearchuk.org/cancerinfo/cancerstats/types/myeloma/incidence/uk-multiple-myeloma-incidence-statistics.

28. Vincent S, Rajkumar S, Vincent, et al. International Myeloma Working Group updated criteria for the diagnosis of multiple myeloma. The Lancet Oncology. 2014;12(15):538-48.

29. Waxman AJ, Mink PJ, Devesa SS, et al., 2010 Racial disparities in incidence and outcome in multiple myeloma: a population-based study. Blood., 116(25): 5501-5506.

30. Wildes TM, Rosko A, Tuchman SA. Multiple myeloma in the older adult: better prospects, more challenges. J Clin Oncol. 2014;32(24):2531-40.

\section{Figures}

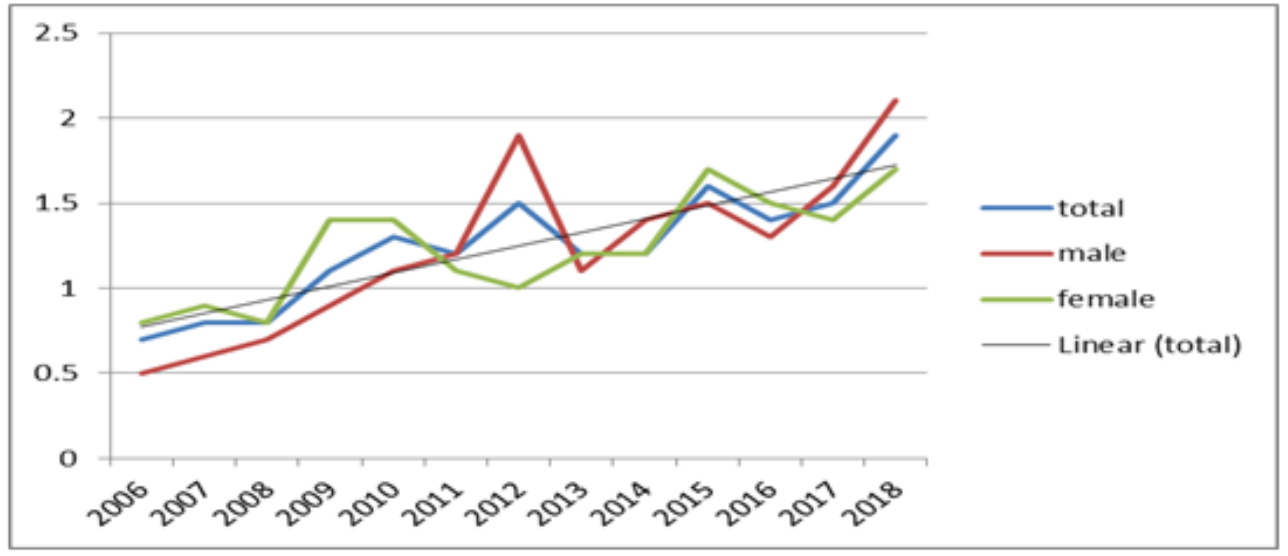

\section{Figure 1}

The incidence rates of MM in Armenia for the period 2006-2018. 


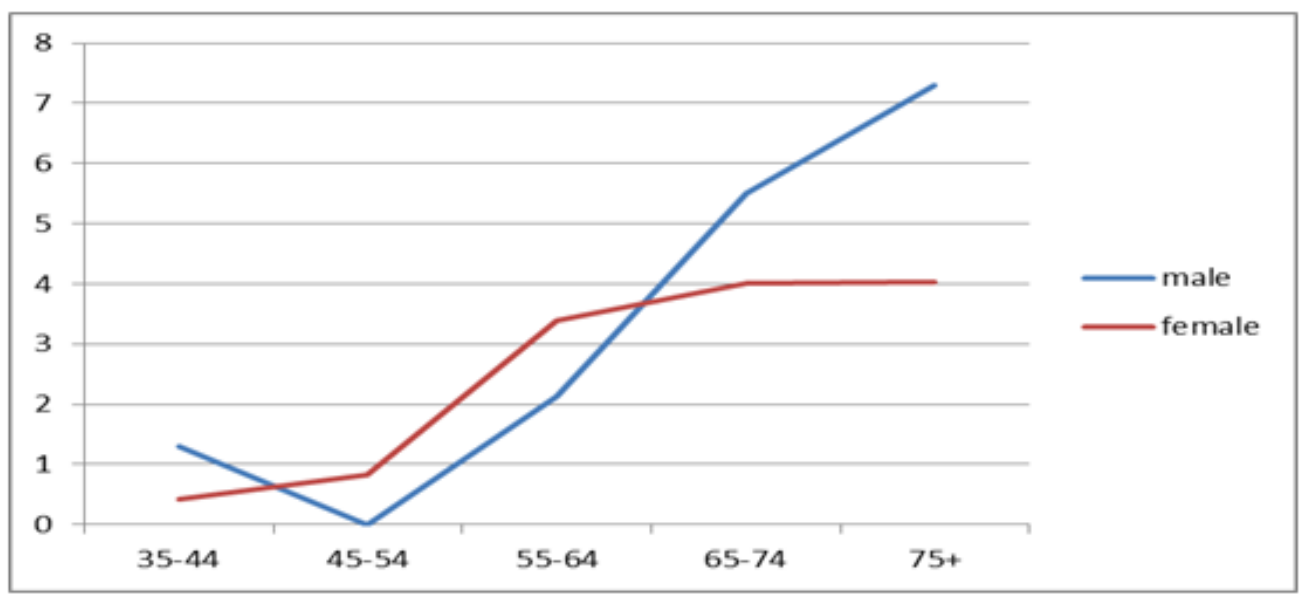

\section{Figure 2}

The age-specific incidence rates of MM in Armenia 2006

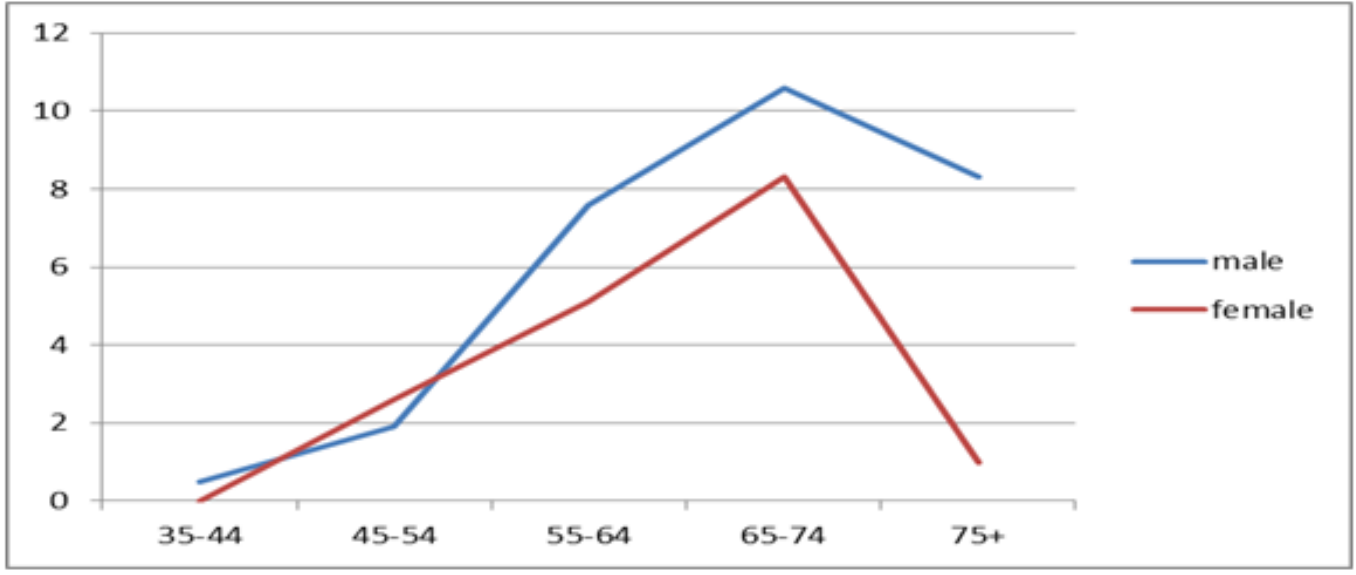

Figure 3

The age-specific incidence rates of MM in Armenia 2018

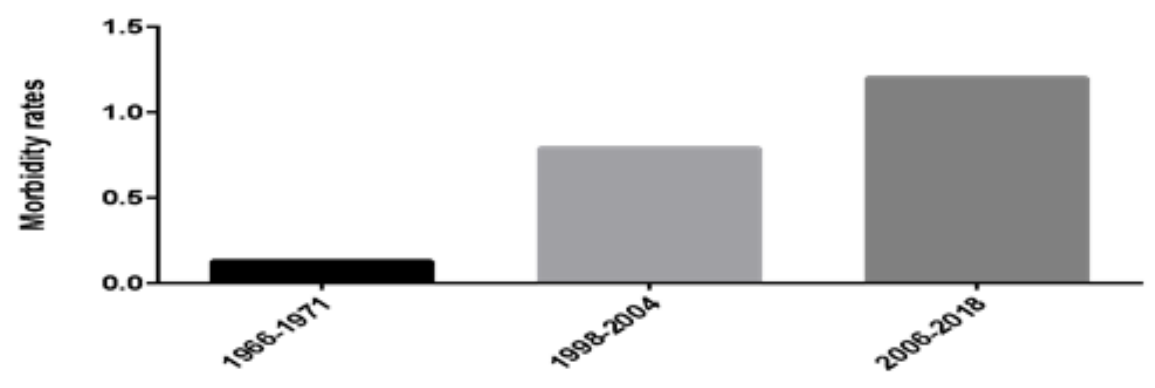

Figure 4

Comparison of incidence rates of MM for the 2006-2018, 1998-2004, and 1966-1971. 